\title{
Pengaruh Profitabilitas, Likuiditas Dan Ukuran Perusahaan Terhadap Struktur Modal
}

\author{
Inggrid Liang dan Khairina Natsir \\ Program Studi S1 Manajemen Fakultas Ekonomi \\ Universitas Tarumanagara, Jakarta \\ Email: inggrid.115150005@stu.untar.ac.id
}

\begin{abstract}
The purpose of this research is to investigate the influence of profitability, liquidity and firm size on the capital structure. The population is the Manufacturing Company of the Consumer Goods Industrial Sector listed in the Indonesia Stock Exchange in 2013-2017. The sample used in this research consists of 31 manufacturing companies in the consumer goods industrial sector. This research use the non probability sampling and purposive sampling technique. The analysis is performed by using Panel Data Regression Analysis with random effect method in testing the hypothesis. The result shows that profitability have a negative effect on capital structure, liquidity have a negative effect on capital structure and firm size have a positive effect on capital structure.
\end{abstract}

Keyword: Profitability, Liquidity, Firm Size, Capital Structure

\begin{abstract}
Abstrak: Tujuan penelitian ini adalah untuk mengetahui pengaruh profitabilitas, likuiditas dan ukuran perusahaan terhadap struktur modal. Populasi dalam penelitian ini adalah Perusahaan Manufaktur Sektor Industri Barang Konsumsi yang terdaftar di Bursa Efek Indonesia pada tahun 2013-2017. Sampel yang digunakan terdiri dari 31 perusahaan manufaktur sektor industri barang konsumsi. Metode pengambilan sampel menggunakan non probability sampling dan teknik purpsive sampling. Analisis dilakukan dengan menggunakan Analisis Regresi Data Panel dengan metode Random Effect dalam pengujian hipotesis. Hasil menunjukkan bahwa profitabilitas berpengaruh negatif terhadap struktur modal. Likuiditas berpengaruh negatif terhadap struktur modal. Ukuran perusahaan berpengaruh positif terhadap struktur modal.
\end{abstract}

Kata kunci: Profitabilitas, Likuiditas, Ukuran Perusahaan, Struktur Modal

\section{LATAR BELAKANG}

Setiap perusahaan berlomba-lomba untuk berusaha melakukan inovasi dan pengembangan terhadap produk-produk yang dimiliki agar dapat mengantisipasi persaingan yang semakin ketat baik dari perusahaan besar maupun dari perusahaan kecil. Untuk melakukan inovasi dan pengembangan produk perusahaan tentunya membutuhkan biaya. Oleh karena itu, masalah pendanaan yang berkaitan dengan struktur modal sangatlah penting dalam suatu perusahaan.

Keputusan pendanaan merupakan salah satu keputusan yang diambil oleh manajer keuangan yang sangat penting karena dapat mempengaruhi kegiatan operasional dalam suatu perusahaan. Baik atau tidaknya suatu keputusan pendanaan dalam suatu perusahaan dapat 
dilihat dari struktur modal. Dalam mengambil keputusan pendanaan suatu perusahaan, seorang manajer keuangan harus mampu mengalokasikan biaya modal yang akan digunakan.

Modal merupakan salah satu hal yang paling penting dalam suatu perusahaan. Perusahaan harus memiliki modal jika ingin merintis maupun mengembangkan usaha. Oleh karena itu, suatu perusahaan harus menetapkan berapa besarnya jumlah dari modal yang dibutuhkan agar dapat membiayai usahanya.

Penetapan struktur modal yang dilakukan oleh perusahaan akan dipengaruhi juga oleh beberapa faktor-faktor seperti profitabilitas, penjualan, ukuran perusahaan, pembagian dividen, likuiditas, pajak, dan sikap manajemen. Berdasarkan penjelasan diatas peneliti akan membahas 3 faktor yang mempengaruhi pemilihan struktur modal (debt to total asset ratio) saja, yaitu profitabilitas (return on asset), likuiditas (current ratio) dan ukuran perusahaan (SIZE).

\section{KAJIAN TEORI}

Pecking Order Theory. Menurut (Maryanti, 2016) pecking order theory merupakan teori yang dapat memberikan gambaran dimana perusahaan lebih mengutamakan laba ditahan sebagai sumber pendanaan, kemudian hutang dan penerbitan saham sebagai pilihan terakhir. Dalam teori pecking order dijelaskan beberapa alasan mengapa dalam pengambilan keputusan untuk pendanaan perusahaan memiliki urutan preferensi karena perusahaan yang menguntungkan atau profitable akan cenderung menggunakan pendanaan eksternal dalam jumlah yang sedikit, sedangkan bagi perusahaan dengan tingkat keuntungan yang rendah biasanya menggunakan pendanaan eksternal karena dana internal yang tidak lagi mencukupi kebutuhan pendanaan (Indriani, Widyarti dan Fitria, 2017).

Signaling Theory. Menurut (Irvan, 2016) Isyarat atau signal merupakan sebuah tindakan yang diambil manajemen untuk memberi petunjuk bagi investor tentang bagaimana manakemen melihat prospek perusahaan tersebut. Teori signaling yang dikembangkan oleh (Chandra, 2015) mengatakan teori pensinyalan digunakan guna memberikan sinyal pada investor bahwa akan timbul pengembalian yang lebih tinggi di masa depan.

Struktur Modal. Struktur Modal perusahaan didefinisikan sebagai kombinasi khusus dari hutang, ekuitas dan sumber lain yang digunakan sebagai sumber pendanaan dalam kegiatan bisnisnya (Md-yusuf, Yunus, Zahraatul dan Supaat, 2013). (Sartono, 2001) mendefinisikan profitabilitas sebagai kemampuan perusahaan memperoleh laba dalam hubungannya dengan penjualan, total aktiva maupun modal sendiri. (Septiani dan Suaryana, 2018) mengatakan bahwa struktur modal yang optimal yaitu struktur modal yang diprediksi dapat menghasilkan biaya modal rata-rata tertimbang yang paling rendah agar dapat memaksimalkan nilai perusahaan. Menurut (Dewi dan Dana, 2017), perusahaan yang menggunakan pendanaan dengan utang dapat meningkatkan tingkat pengembalian yang akan dibagikan kepada para pemegang saham dalam perusahaan tersebut, namun dengan menggunakan hutang sebagai salah satu sumber pendanaan perusahaan, maka dapat meningkatan risiko keuangan dimana perusahaan harus mampu melunasi utang tersebut pada waktu jatuh tempo yang telah ditentukan dan juga membayar bunga pinjaman dari hutang tersebut.

Profitabilitas. (Deitiana dan Robin, 2016) menyatakan definisi profitabilitas sebagai hubungan antara pendapatan dan biaya yang dihasilkan dengan menggunakan aset perusahaan baik saat ini dan tetap dalam kegiatan produktif.

Rasio profitabilitas merupakan sebuah rasio yang digunakan untuk menilai dan mengukur seberapa besar kemampuan suatu perusahaan dalam memperoleh keuntungan dan dapat melihat ukuran tingkat efektivitas manajemen pada suatu perusahaan (Kasmir, 2012).

Menurut (Kasmir, 2012), ada beberapa tujuan dari penggunaan rasio profitabilitas, yaitu: (a) Untuk mengukur atau menghitung perolehan laba suatu perusahaan dalam satu periode tertentu. (b) Untuk menilai posisi laba yang diperoleh perusahaan pada tahun sebelumnya 
dengan tahun sekarang. (c) Untuk menilai perkembangan laba perusahaan dari waktu ke waktu. (d) Untuk menilai besarnya laba bersih sesudah pajak yang diperoleh perusahaan dengan modal sendiri. (e) Untuk mengukur produktivitas seluruh dana perusahaan yang digunakan baik yang berasal dari modal pinjaman maupun modal sendiri. (f) Untuk mengukur produktivias dari keseluruhan dana perusahaan yang digunakan baik modal sendiri

Sebuah perusahaan yang memiliki profitabilitas yang lebih besar harus mempunyai leverage dan rasio utang yang lebih banyak, karena perusahaan yang memiliki profitabilitas yang besar akan memiliki risiko kebangkrutan yang lebih rendah (Alipour, Mohammadi dan Derakhshan, 2015).

Likuiditas. Likuiditas merupakan sebuah rasio yang digunakan sehingga kemampuan perusahaan didalam membayar kewajiban jangka pendek dapat diukur (Armelia, 2016). Likuiditas merupakan rasio yang menunjukkan hubungan antara kas dan aset lancar perusahaan lainnya dengan kewajiban lancarnya (Gul, Khan, Razzaq dan Saif, 2015). Rasio Likuiditas (liquidity ratio) merupakan rasio yang digunakan sehingga dapat mengukur kemampuan perusahaan dalam mengembalikan kewajiban lancarnya dengan aset lancar yang tersedia untuk memenuhi kewajiban (Indriani, Widyarti dan Fitria, 2017).

Tingkat likuiditas suatu perusahaan yang cenderung tinggi menunjukkan bahwa kemampuan perusahaan memenuhi kewajiban atau utang jangka pendek (Armelia, 2016). Perusahaan dengan tingkat likuiditas yang tinggi (memiliki lebih banyak aset lancar) cenderung menggunakan lebih banyak pinjaman dana eksternal, karena perusahaan memiliki kemampuan dalam melunasi kewajibannya (Imtiaz, Mahmud dan Malik, 2016).

Ukuran Perusahaan. Menurut (Rahmiati, Tasman dan Melda, 2015), ukuran perusahaan merupakan sebuah skala yang dapat mengklasifikasikan besar kecilnya suatu perusahaan dalam berbagai cara, antara lain melalui total aset, log size, nilai pasar saham, total sales dan lain-lain.

Menurut (Rahmiati, Tasman dan Melda, 2015), jika sebuah perusahaan memiliki ukuran (Firm Size) yang besar maka perusahaan tersebut cenderung akan lebih banyak menggunakan hutang sebagai pendanaannya dibandingkan dengan perusahaan yang memiliki ukuran (Firm Size) yang lebih kecil.

Kerangka penelitian dalam penelitian ini digambarkan seperti gambar dibawah.

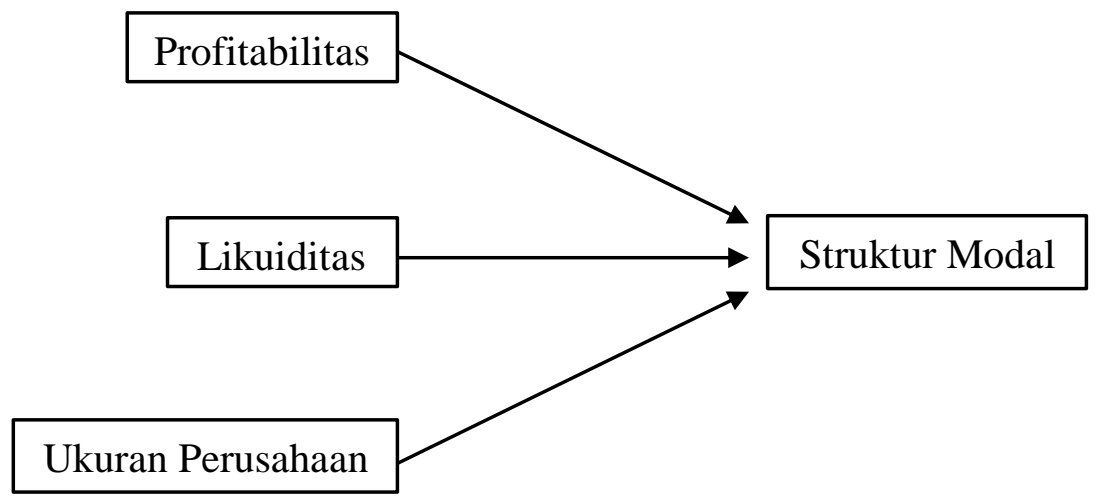

Gambar 1. Kerangka Penelitian

Hipotesis berdasarkan model kerangka penelitian diatas adalah sebagai berikut:

$\mathrm{H}_{1}$ : Profitabilitas berpengaruh terhadap Struktur Modal.

$\mathrm{H}_{2}$ : Likuiditas berpengaruh terhadap Struktur Modal.

$\mathrm{H}_{3}$ : Ukuran Perusahaan berpengaruh terhadap Struktur Modal. 


\section{METODOLOGI}

Desain Penelitian. Penelitian ini menggunakan metode kuantitatif dengan desain penelitian yang bersifat deskriptif yang merupakan sebuah penelitian yang digunakan untuk menguji kebenaran empiris dari suatu hipotesis, yaitu kebenaran mengenai empiris kaitan antardua atau lebih variabel penelitian yang dirumuskan pada hipotesisnya (Aritonang, R., 2007). Penelitian ini menggunakan data panel (pooled data) yang merupakan suatu kombinasi dari data time series dan cross-section (Ajija, Sari, Setianto dan Primanti, 2011).

Objek Penelitian. Penelitian ini difokuskan pada seluruh perusahaan manufaktur sektor industri barang konsumsi yang terdaftar di Bursa Efek Indonesia periode 2013-2017 yang laporan keuangannya diperoleh dari www.idx.co.id. Pemilihan sampel dilakukan dengan menggunakan metode purposive sampling method dengan menggunakan kriteria yang telah ditentukan oleh peneliti yaitu (a) Perusahaan manufaktur sektor barang konsumsi yang terdaftar di Bursa Efek Indonesia (BEI) pada tahun 2013-2017 secara terus menerus, (b) Perusahaan yang melaporkan laporan tahunan secara berturut-turut selama periode 2013-2017, (c) Perusahaan yang memiliki kelengkapan data yang sesuai dengan variabel yang dibutuhkan. Jumlah data yang memenuhi syarat yaitu sebanyak 31 perusahaan.

Operasional Variabel. Variabel operasional dalam penelitian ini terdiri dari profitabilitas, likuiditas dan ukuran perusahaan yang merupakan variabel independent dan struktur modal yang merupakan variabel dependent. Dalam penelitian ini struktur modal diwakili oleh Debt to Total Asset Ratio (DR) yang membandingkan total kewajiban dengan total asset dengan rumus sebagai berikut:

$$
\text { Debt to Asset Ratio (DR) }=\frac{\text { Total Debt }}{\text { Total Asset }}
$$

Profitabilitas diwakili oleh Return on Asset (ROA) yang membandingkan net income dengan total asset dengan rumus sebagai berikut:

$$
\mathrm{ROA}=\frac{\text { Net Income }}{\text { Total Asset }}
$$

Likuiditas dapat diukur dengan Current Ratio (CR) yang membandingkan aset lancar dengan kewajiban lancar dengan formula sebagai berikut:

$$
\text { Current Ratio }=\frac{\text { Current Asset }}{\text { Current Liabilities }}
$$

Sedangkan ukuran perusahaan dapat diukur dengan SIZE dengan perhitungan Log Natural dari total asset sebagai berikut:

$$
\text { Size }=\ln (\text { Total Asset })
$$

Dalam pengujian ini menggunakan Statistik Deskriptif, Uji Multikolinearitas, Uji Model Data Panel, Analisis Regresi Linear Berganda, Uji-t, dan Uji Koefisien Determinasi $\left(\mathrm{R}^{2}\right)$. 
Analisis Statistik Deskriptif. Analisis statistik deskriptif berguna untuk mengetahui informasi mengenai nilai rata-rata (mean), nilai tengah (median) standar deviasi, nilai minimum, dan nilai maksimum sehingga dapat mempermudah pembahasan dalam penelitian.

Hasil analisis statistik deskriptif menunjukkan bahwa nilai mean (nilai rata-rata) debt to total asset ratio (DR) pada uji statistik deskriptif yaitu sebesar 0.390705 dengan median (nilai tengah) sebesar 0.380000 dan standar deviasi sebesar 0.208421. Sementara nilai minimum debt ratio pada perusahaan manufaktur sektor barang konsumsi tahun 2013-2017 yaitu sebesar 0.003000 dan nilai maksimum sebesar 1.248600.

Hasil analisis statistik deskriptif menunjukkan bahwa nilai rata-rata (mean) dari ROA (return on asset) pada uji statistik deskriptif yaitu sebesar 0.101612 dengan nilai tengah (median) sebesar 0.081400 dan standar deviasi sebesar 0.128438. Sementara itu, nilai minimum return on asset (ROA) pada perusahaan manufaktur sektor barang konsumsi tahun 2013-2017 yaitu sebesar -0.208000 dan nilai maksimum sebesar 0.670000.

Hasil analisis statistik deskriptif menunjukkan bahwa nilai rata-rata (mean) dari current ratio (CR) pada uji statistik deskriptif yaitu sebesar 2.588562 dengan nilai tengah (median) sebesar 2.063000 dan standar deviasi sebesar 1.874676. Sementara itu, nilai minimum current ratio (CR) pada perusahaan manufaktur sektor barang konsumsi tahun 2013-2017 yaitu sebesar 0.053500 dan nilai maksimum sebesar 10.30000 .

Hasil analisis statistik deskriptif menunjukkan bahwa nilai rata-rata (mean) dari SIZE pada uji statistik deskriptif yaitu sebesar 28.70332 dengan nilai tengah (median) sebesar 28.37336 dan standar deviasi sebesar 1.538888. Sementara itu, nilai minimum ukuran perusahan (SIZE) pada perusahaan manufaktur sektor barang kosumsi tahun 2013-2017 yaitu sebesar 25.32764 dan nilai maksimum sebesar 32.15098.

Uji Multikolinearitas. Menurut (Ajija, Sari, Setianto dan Primanti, 2011) Multikolineritas memperlihatkan adanya hubungan linear yang sempurna atau pasti, diantara beberapa atau seluruh variabel yang menjelaskan dari model regresi.

Hasil uji multikolinearitas menunjukkan bahwa antar variabel bebas tidak memiliki korelasi yang lebih dari 0.8 sehingga dapat diambil kesimpulan bahwa profitabilitas (Return on Asset), likuitidas (Current Ratio) dan Ukuran Perusahaan (SIZE) tidak mengalami multikolinearitas dalam model regresi pada perusahaan manufaktur sektor industri barang konsumsi yang digunakan.

Uji Chow. Uji likelihood atau uji chow dilakukan agar peneliti dapat menentukan apakah metode Common Effect atau Fixed Effect yang paling tepat untuk digunakan dalam mengestimasi data panel.

Hasil uji chow menunjukkan nilai cross-section F dan cross-section Chi-square dibawah nilai taraf signifikan alpha $(\alpha)$ yaitu 0,05 berarti $\mathrm{H}_{0}$ ditolak sehingga lebih baik menggunakan fixed effect model daripada pooled least square model dalam penelitian ini. Sehingga penelitian Uji Hausman akan kembali di teliti untuk melihat penelitian ini menggunakan fixed effect model ataukah random effect model.

Uji Hausman. Uji hausman dilakukan agar peneliti dapat menentukan pendekatan manakah antara model fixed effect atau model random effect yang lebih baik untuk digunakan dalam mengestimasi data panel.

Hasil uji hausman menunjukkan nilai probabilitas cross-section random pada uji hausman yaitu sebesar 0.1510 , lebih besar dari alpha $(\alpha)$ yang sebesar 0.05 . Berdasarkan hasil tersebut maka dapat disimpulkan bahwa hipotesis nol $\left(\mathrm{H}_{0}\right)$ tidak ditolak yang artinya metode random effect yang lebih baik digunakan untuk mengestimasi data panel daripada metode fixed effect. 
Analisis Regresi Berganda. Regresi berganda digunakan agar dapat mengetahui pengaruh variabel independen terhadap variabel dependen baik secara parsial ataupun bersama-sama.

Tabel 1. Hasil Analisis Regresi Berganda

\begin{tabular}{crrrr}
\hline \hline Variable & Coefficient & Std. Error & t-Statistic & Prob. \\
\hline \hline ROA & -0.317087 & 0.132219 & -2.398194 & 0.0177 \\
CR & -0.059116 & 0.008331 & -7.095881 & 0.0000 \\
SIZE & 0.022442 & 0.016611 & 1.351071 & 0.1787 \\
C & -0.068214 & 0.475626 & -0.143420 & 0.8861 \\
\hline \hline
\end{tabular}

Tabel diatas memperlihatkan bahwa struktur modal (debt to total asset ratio/ DR) akan memiliki nilai -0.068214 satuan jika variabel independennya dianggap nol. Jika terjadi kenaikan satu satuan pada profitabilitas (return on assets/ ROA) dan variabel independen lain dianggap konstan maka struktur modal (debt to total asset ratio/ DR) akan turun sebesar 0.059116 satuan. Jika terjadi kenaikan satu satuan pada likuiditas (current ratio/ CR) dan variabel bebas lain dianggap konstan maka struktur modal (debt to total asset ratio/ DR) akan turun sebesar 0.057876 satuan. Jika terjadi kenaikan satu satuan pada ukuran perusahaan (SIZE) dan variabel bebas lain dianggap konstan maka struktur modal (debt to total asset ratio/ DR) akan naik sebesar 0.022442 satuan.

Uji-t. Uji-t dilakukan sehingga dapat mengetahui pengaruh masing-masing variabel independen terhadap variabel dependen.

Tabel 2. Hasil Uji-t

\begin{tabular}{crrrr}
\hline \hline Variable & Coefficient & Std. Error & t-Statistic & Prob. \\
\hline \hline ROA & -0.317087 & 0.132219 & -2.398194 & 0.0177 \\
CR & -0.059116 & 0.008331 & -7.095881 & 0.0000 \\
SIZE & 0.022442 & 0.016611 & 1.351071 & 0.1787 \\
C & -0.068214 & 0.475626 & -0.143420 & 0.8861 \\
\hline \hline
\end{tabular}

Hasil uji-t menunjukkan bahwa hasil probabilitas dari Profitabilitas (return on asset) ROA) sebesar 0.0177 yang berarti lebih kecil dari tingkat keyakinan yaitu sebesar 0.05 , artinya $\mathrm{H}_{01}$ ditolak yang berarti Profitabilitas (return on asset/ ROA) memiliki pengaruh yang signifikan terhadap Struktur Modal (debt to total asset ratio/ DR) pada tingkat keyakinan sebesar $95 \%$.

Hasil probabilitas dari Likuiditas (current ratio/ CR) sebesar 0.0000 yang berarti lebih kecil dari tingkat keyakinan yaitu sebesar 0.05 , artinya $\mathrm{H}_{02}$ ditolak yang berarti Likuiditas (current ratio/ CR) memiliki pengaruh yang signifikan terhadap Struktur Modal (debt to total asset ratio/DR) pada tingkat keyakinan sebesar $95 \%$.

Hasil probabilitas dari Ukuran Perusahaan (SIZE) sebesar 0.1787 yang berarti lebih besar dari tingkat keyakinan yaitu sebesar 0.05 , artinya $\mathrm{H}_{03}$ tidak ditolak yang berarti Ukuran Perusahaan (SIZE) tidak memiliki pengaruh yang signifikan terhadap Struktur Modal (debt to total asset ratio/DR) pada tingkat keyakinan sebesar $95 \%$. 
Uji Koefisien Determinasi $\left(\mathbf{R}^{2}\right)$. Uji koefisien determinasi atau uji $\mathrm{R}^{2}$ dilakukan agar dapat melihat seberapa besar perubahan dari variasi variabel dependen dapat dijelaskan oleh variasi variabel independen.

Tabel 3. Uji Koefisien Determinasi $\left(\mathrm{R}^{2}\right)$

\begin{tabular}{|l|l|}
\hline R-squared & 0.271853 \\
\hline Adjusted R-squared & 0.257386 \\
\hline
\end{tabular}

Dari hasil yang diperlihatkan pada tabel 4.10 dapat dilihat bahwa nilai adjusted $R$ square dari DR yakni sebesar 0.257386 yang artinya sebesar $25.73 \%$ variabel Struktur Modal (Debt to Total Asset Ratio/ DR) dapat dijelaskan oleh Profitabilitas (Return on Asset/ ROA), Likuiditas (Current Ratio/ CR) dan Ukuran Perusahaan (SIZE) dan $74.27 \%$ di pengaruhi oleh variabel lain diluar dari variabel independen dalam penelitian ini.

\section{DISKUSI}

Hasil analisis dalam pengujian memperlihatkan bahwa Profitabilitas (ROA) memiliki pengaruh negatif signifikan terhadap Struktur Modal (DR). Hasil analisis dalam pengujian memperlihatkan bahwa Likuiditas (CR) memiliki pengaruh negatif signifikan terhadap Struktur Modal (DR). Hasil analisis dalam pengujian memperlihatkan bahwa Ukuran Perusahaan (SIZE) memiliki pengaruh positif tidak signifikan terhadap Struktur Modal (DR).

\section{PENUTUP}

(1) Berdasarkan hasil pengujian data yang dilakukan dalam penelitian ini dengan menggunakan EViews pada perusahaan manufaktur sektor industri barang konsumsi tahun 2013-2017, struktur modal memiliki pengaruh terhadap Return on Asset, Current Ratio dan SIZE. (2) Keterbatasan dalam penelitian ini dikarenakan: (1) Penelitihan hanya menggunakan 3 variabel bebas terhadap 1 variabel terikat, (2) Periode penelitian yang digunakan hanya dari tahun 2013-2017, (3) Penelitian ini hanya menggunakan perusahaan manufaktur sektor industri barang konsumsi yang terdaftar di Bursa Efek Indonesia dengan 31 sampel perusahaan yang digunakan sebagai objek penelitian. (3) Berdasarkan hasil dan keterbatasan maka saran yang dapat diberikan untuk melakukan penelitian selanjutnya yaitu diharapkan hasil penelitian ini dapat digunakan sebagai bahan pertimbangan dalam proses pengambilan keputusan pendanaan dalam perusahaan, bagi penelitian selanjutnya diharapkan agar dapat menambahkan variabelvariabel lainnya dalam penelitian yang berhubungan dengan struktur modal, dapat menambah periode penelitian tidak hanya terbatas pada periode 2013-2017, dan dapat menambah objek penelitian.

\section{DAFTAR PUSTAKA}

Ajija, S. R., Sari, D. W., Setianto, R. H., dan Primanti, M. R. (2011). Cara Cerdas Menguasai EViews. Jakarta: Salemba Empat.

Aritonang, R. L. (2007). Riset Pemasaran: Teori \& Praktik. Bogor: Ghalia Indonesia.

Alipour, M., Mohammadi, M. F. S., and Derakhshan, H. (2015). Determinants of Capital Structure: An Empirical Study of Firms in Iran. International Journal of Law and Management, 57(1), 53-83. 
Armelia, Shelly. (2016). Pengaruh Ukuran Perusahaan, Profitabilitas, Likuiditas dan Struktur Aktiva Terhadap Struktur Modal Perusahaan Manufaktur Go Publik (Studi Sektor Kosmetik dan Keperluan Rumah Tangga). Jurnal Online Mahasiswa Fakultas Ilmu Sosial dan Ilmu Politik Universitas Riau (JOM FISIP UNRI), 3(2), 1-13.

Chandra, Teddy. (2015). The Determinants of the Capital Structure: Empirical Evidence from Indonesian Stock Exchange Companies. Journal of KASMERA, 43(2), 76-87.

Deitiana, T., and Robin. (2016). The Effect of Firm Size, Profitability, Tangibility, Non-Debt Tax Shield and Growth to Capital Structure on Banking Firms Listed in Indonesia Stick Exchange From 2007-2012. South East Asia Journal of Contemporary Business, Economics and Law, 10(1), 37-44.

Gul, S., Khan, M. B., Razzaq, N., and Saif. N. (2012). How Firm Charateristics Affect Capital Structure in Banking and Insurance Sectors (The Case of Pakistan). European Journal of Business and Management, 4(12), 6-16.

Imtiaz, M. F., Mahmud, K., and Mallik, A. (2016). Determinants of Capital Structure and Testing of Applicable Theories: Evidence from Pharmaceutical Firms of Bangladesh. International Journal of Economics and Finance, 8(3), 23-32.

Indriani, A., Widyarti, E. T., dan Fitria, S. (2017). Capital Structure Perbankan Syariah di Asia Tenggara: Sebuah Pendekatan Empiris. Al Tijarah, 3(2), 97-118.

Irvan, Thomi. (2016). Pengaruh Profitabilitas dan Likuiditas Terhadap Struktur Modal Perusahaan Asuransi (Yang Terdaftar di Bursa Efek Indonesia (BEI) Periode 2012-2014). Jurnal Manajemen Bisnis, 3(2), 1-14.

Kasmir. (2012). Analisis Laporan Keuangan (1 ${ }^{\text {st }}$ ed.). Jakarta: PT Raja Grafindo Persada.

Maryanti, Eny. (2016). Analisis Profitabilitas, Pertumbuhan Perusahaan, Pertumbuhan Penjualan dan Struktur Aktiva Terhadap Struktur Modal Pada Perusahaan Sektor Industri Barang Konsumsi yang Terdaftar di Bursa Efek Indonesia. Riset Akuntansi dan Keuangan Indonesia, 1(2), 143-151.

Md-yusuf, M., Yunus, F. M., Zahraatul, N., and Supaat, L. (2013). Determiants of Capital Structure in Malaysia Electrical and Electronic Sector. International Journal of Social, Management, Economics and Business Engineering, 7(6), 676-681.

Sartono, A. (2016). Manajemen Keuangan Teori dan Aplikasi Edisi 4. Yogyakarta: BPFE.

Septiani, N. P. N., dan Suaryana, I. G. N. A. (2018). Pengaruh Profitabilitas, Ukuran Perusahaan, Struktur Aset, Risiko Bisnis dan Likuiditas pada Struktur Modal. E-Jurnal Akuntansi Universitas Udayana, 22(3), 1682-1710.

Rahmiati, Tasman, A., dan Melda, Y. (2015). Pengaruh Profitabilitas dan Ukuran Perusahaan Terhadap Struktur Modal Perusahaan Property dan Real Estate Yang Terdaftar di Bursa Efek Indonesia Tahun 2010-2013. Seminar Nasional Ekonomi Manajemen dan Akuntansi (SNEMA) Fakultas Ekonomi Universitas Negeri Padang, 325-333. 